\title{
Symmetrica: test case for transportation electrification research
}

\author{
Amro M. Farid ${ }^{1,2}$
}

\begin{abstract}
In recent years, transportation electrification has emerged as a trend to support energy efficiency and $\mathrm{CO}_{2}$ emissions reduction targets. The true success, however, of this trend depends on the successful integration of electric vehicles into the infrastructure systems that support them. In effect, electric vehicles and their supporting charging infrastructure couple the transportation and electrical power systems into a nexus. In the absence of fully deployed large scale electrified transportation systems, this paper argues the need for a transportation electrification test case analogous to those used ubiquitously in the power systems engineering field. It then presents such a test case; aptly called Symmetrica. It consists of a multi-modal electrified transportation system topology, an electric power topology, and activity-based use case data that spans transportation and charging. The paper concludes with several potential research areas where the test case may be applied.
\end{abstract}

Keywords: Transportation electrification; Electric vehicles; Smart grids; Intelligent transportation systems; Transportation-electricity nexus

\section{Background}

In recent years, electrified transportation has emerged as a trend to support energy efficiency and $\mathrm{CO}_{2}$ emissions reduction targets (Anair and Mahmassani 2012; Karabasoglu and Michalek 2013; Pasaoglu et al. 2012; Raykin et al. 2012; Yang and Wu 2012). Relative to their internal combustion vehicle (ICV) counterparts, electric vehicles (EV), be they trains, buses, or cars, have a greater "well-to-wheel" energy efficiency (Soylu 2011; Yang and $\mathrm{Wu}$ 2012). They also have the added benefit of not emitting any carbon dioxide in operation and rather shift their emissions to the existing local fleet of power generation facilities (Litman 2013).

The true success of electric vehicles depends on their successful integration with the infrastructure systems that support them. From a transportation perspective, the typical performance of conventional electric cars may have a range of only $150 \mathrm{~km}$ (Skippon and Garwood 2011) but may still require several hours to charge (Pointon 2012). This affects when a vehicle can begin its journey and the

Correspondence: amfarid@dartmouth.edu; amfarid@mit.edu

${ }^{1}$ Thayer School of Engineering at Dartmouth, 14 Engineering Drive, Hanover, $\mathrm{NH}$ 03755, USA

${ }^{2}$ Research Affiliate MIT Mechanical Engineering, 77 Massachusetts Avenue, Cambridge, MA 02139, USA route it intends to take. From an electricity perspective, the charging loads can draw large power demands which may exceed transformer ratings, cause undesirable line congestion, or voltage deviations (Al Junaibi et al. 2013; Al Junaibi 2013; Al Junaibi and Farid 2013; Kassakian et al. 2011). These loads may be further exacerbated temporally by similar charging patterns driven by similar work and travel lifestyles or geographically by the relative sparsity of charging infrastructure in high demand areas (Al Junaibi and Farid 2013). In effect, the electric vehicles and their supporting charging infrastructure couple the transportation and electrical systems into a nexus.

Definition 1. Transportation-Electricity Nexus (TEN) (Farid 2015a; Viswanath and Farid 2014): A system-ofsystems composed of a system with the artifacts necessary to describe at least one mode of transport united with an interdependent system composed of the artifacts necessary to generate, transmit, distribute and consume electricity.

As a result, the performance in the transportation domain can not be studied independently of the performance in the electrical domain. Furthermore, efforts to operate and control the performance in either domain requires an assessment model whose scope includes the functionality of both systems.

\section{Springer}

(C) 2015 Farid. Open Access This article is distributed under the terms of the Creative Commons Attribution 4.0 International License (http://creativecommons.org/licenses/by/4.0/), which permits unrestricted use, distribution, and reproduction in any medium, provided you give appropriate credit to the original author(s) and the source, provide a link to the Creative Commons license, and indicate if changes were made. 
The planning, operation and assessment methodologies for a transportation electricity nexus are still very much in the course of development (Farid 2015a; Viswanath and Farid 2014). Although, the individual fields of transportation systems engineering (Barcelo and Kuwahara 2008; Barcelo 2010; Treiber and Kesting 2013) and power systems engineering (Gomez Exposito et al. 2008; Wood and Wollenberg 2014) are well established, the union of these two systems requires new approaches beyond those of each field separately. For example, power systems research has recently made several contributions in coordinated charging (Clement-Nyns et al. 2010; Dyke et al. 2010; Erol-Kantarci et al. 2012; Gan et al. 2013; Gong et al. 2013; Lopes et al. 2011; Ma et al. 2012; Palensky and Dietrich 2011; Pieltain Fernandez et al. 2011; Qian et al. 2011; Saber and Venayagamoorthy 2011; Sortomme et al. 2011) and "vehicle-to-grid" (Kempton and Tomić 2005; Sovacool and Hirsh 2009; Su et al. 2012) stabilization schemes. And yet, these works assume a stationary electric vehicle - thus eliminating its existential nature as a transportation artifact.

In the absence of fully deployed large scale electrified transportation systems, it is necessary to study their future potential in a simulation environment. As shown in Fig. 1, such study consists of five mutually compatible elements. First, a TEN test case provides the input numerical data that serves as the basis for the computational research. Next, a TEN dynamic model provides the equations of motion that describes the behavior of the physical system. It is important to recognize that while the test case must be sufficient for the dynamic model, such a model is not necessarily unique. As discussed in Section 'Usage of power system test cases', a modeler may choose or design one of several models depending on the analytical questions they wish to study. Third, a numerical simulation engine evolves the test case data using the dynamic model's equation of motion. As discussed in Section 'Usage of power system test cases', the choice of a simulation engine may come with entirely different numerical and computation methods which may affect not just simulation performance but also results. Fourth, the simulation results must be analyzed with respect to a set of relevant performance measures and/or life cycle properties. Finally, it is desirable that the simulation environment allow the potential for new policies and regulations which appear as planning and operations control methods that serve to shape the TEN's behavior to a more a desirable performance.

The evaluation framework provided by Fig. 1 sheds light on the status of the existing literature. Thus far, to our knowledge, only three studies have considered the coupling between the kinematic and electrical states in a TEN. A simplified (at $10 \%$ scale) study based on the city of Berlin road transportation network has been implemented on MATSIM (Galus et al. 2012). It assumed a home-charging (i.e. always available) use case and thus neglected the impacts of charging station capacity on the power system as well as on the power system. The usage of MATSIM has two implications. It's in-built traffic model is mesoscopic and therefore average velocities are used to statically estimate the evolution of EV battery state of charge. Second, its simulation engine provides convenient parallel computing. The first full scale electric vehicle integration study (i.e. 1e6 vehicles) was completed in the city of Abu Dhabi (Al Junaibi et al. 2013; Al Junaibi 2013; Al Junaibi and Farid 2013) using the Clean Mobility Simulator (Sonoda et al. 2012). The study also assumed an EV-taxi use case and therefore proposed several charging station topologies as data. Unlike MATSIM, the Clean Mobility Simulator uses a microscopic dynamic traffic model coupled with a detailed dynamical model of electric vehicle characteristics to estimate state of charge. The Abu Dhabi study, unlike (Galus et al. 2012), explicitly included capacity constraints in the transportation, charging, and electrical power infrastructure. Therefore, it sought a more holistic approach to system performance measurement. "Quality of Service" (QOS) (Al Junaibi et al. 2013; Al Junaibi 2013; Al Junaibi and Farid 2013) was introduced as a transportation performance measure to address the availability concerns expressed in EV adoption public attitude surveys. Meanwhile, power system line and bus safety criteria were introduced on the

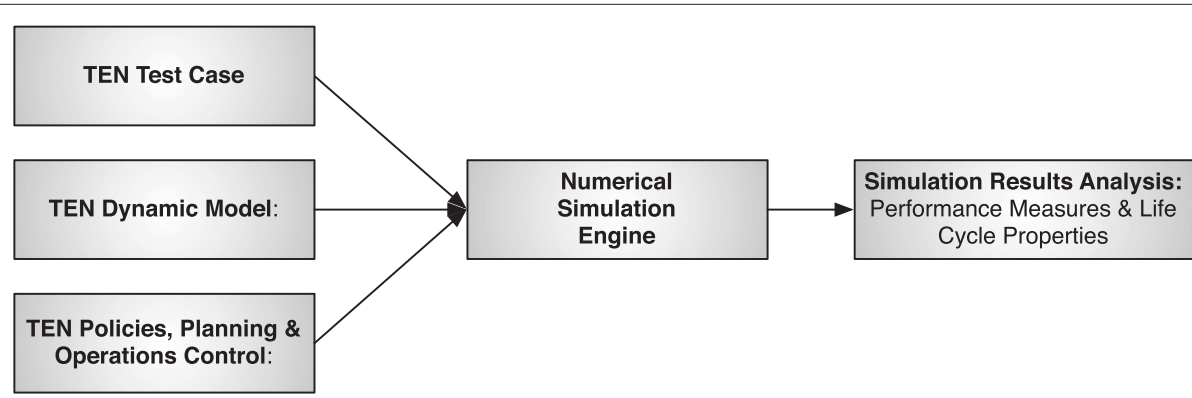

Fig. 1 Simulation-Based Evaluation of a Transportation-Electricity Nexus 
basis of IEEE reliability standards (Al Junaibi et al. 2013; Junaibi 2013; Junaibi and Farid 2013). Finally, a third study sought to compare plug-in electric and online electric vehicles (Ahn et al. 2013; Kim et al. 2013) based upon their fundamentally different vehicle availabilities and charging requirements (Farid 2015a). It used a custom-built parallelized transportation-electrification simulator based on a hybrid dynamic model (Farid 2015a; Viswanath and Farid 2014). None of these studies specifically included the power system topology of their respective geographies.

In light of this literature, this paper's contribution is two fold. First, it argues the need for a transportation electrification test case analogous to those used ubiquitously in the power systems engineering field. Such a test case can be instrumental in the scientific development of the transportation electrification field as an area of systems research. Furthermore, it can mitigate the inherent challenges of national security and individual data privacy that arise from the nature of the transportation electricity nexus. Second, it presents a fully developed transportation-electricity nexus test case; aptly named "Symmetrica". It consists of a multi-modal electrified transportation system topology, an electric power topology, and activity-based use case data that spans transportation and charging. By well-situating the developed test case, this work both identifies some of the systems challenges in transportation electrification research and points to interesting directions for their resolution.

The paper, therefore, proceeds as follows. Section 'The need for a transportation electrification test case' argues the need for a transportation electrification test case. Section 'Transportation-electrification test case' then presents the test case in its entirety in the context of its desirable characteristics. Section 'Potential applications of the transportation electrification test case' discusses some of the potential systems research applications in this field. The paper is brought to a conclusion in Section 'Conclusion'.

\section{The need for a transportation electrification test case}

This section provides a rationale for the development of a transportation electrification test case. It draws upon previous experiences from the power systems engineering, and transportations systems engineering fields while also considering the emerging trends unique to electrified transportation systems.

\section{Usage of power system test cases}

The usage of test cases in the power systems field is the norm. In 1979, the Application of Probability Methods Subcommittee of the IEEE Power Systems Engineering Committee developed the IEEE Reliability Test System
(IEEE RTS) (Subcommittee 1979). It was subsequently revised in 1986 (Allan et al. 1986) and 1996 (Grigg et al. 1999). Since that time, several publicly accessible internetbased test case repositories have emerged (Farid 2015b; IEEE PES Distribution System Analysis Subcommittee's Distribution Test Feeder Working Group 2015; Kavasseri and Ababei 2015; University of Washington Electrical Engineering 2015; Zimmerman et al. 2011). Collectively, they fulfill the original intention of power system test cases: "to satisfy the need for a standardized database to test and compare results from different power system reliability evaluation methodologies" (Grigg et al. 1999). These include power flow analysis, stability studies, state estimation, and contingency analysis (Gomez Exposito et al. 2008; Wood and Wollenberg 2014); all of which investigate different power system performance measures and provide different insights into the reliability of the grid. Furthermore, even in a single study such as power flow analysis, different numerical methods such as Newton-Raphson and Gauss-Seidel are applied depending on the computational environment and convergence requirements. The same committee also recognized that generic test cases can be designed to have universal and/or hybrid characteristics so as to objectively compare evaluation techniques independent of system specific results (Grigg et al. 1999). In that regard, test cases serve a complementary role to data drawn from specific real power systems which would likely exhibit only a subset of the desired characteristics. Given Definition 1 as a superset of the electric power grid, similar reliability studies will ultimately be required when studying a transportationelectricity nexus.

\section{Preservation of critical infrastructure security}

Another reason for the usage of test cases is the recognition that real data from a specific system is likely sensitive to critical infrastructure security (Committee on Increasing National Resilience to Hazards and Disasters and Committee on Science Engineering and Public Policy 2012; Department of Homeland Security 2013; Haimes et al. 2008; The White House: Office of the Press Secretary 2013). The security and economic prosperity of daily life depend on functional transportation and power systems. On the power system side, specific system data which may be used to conduct reliability studies and pinpoint operational weaknesses in the power grid may also be subsequently used nefariously by unauthorized personnel. The usage of generic test cases allows the development of reliability methods in the power systems field without sharing sensitive information. On the transportation system side, specific system data (i.e. GIS data) is inevitably available to support commercial and personal daily activity. As a result, much transportation system research uses specific system data. Developing 
methods in transportation system resilience are able to pinpoint the transportation system artifacts that have the greatest impact on system vulnerability when eliminated (Albert et al. 2000; Farid 2015d; 2014; Harary and Hayes 1993; Holme et al. 2002; Ip and Wang 2011; Najjar and Gaudiot 1990; Rosenkrantz et al. 2009; Salles and Marino 2011; Whitson and Ramirez-Marquez 2009). That said, one must distinguish between the data necessary to support public activity (i.e. maps) and the detailed data (i.e. capacities, traffic patterns) required to conduct accurate and dynamic resilience studies. While the former can remain publicly available, the latter can remain proprietary; thus motivating the development of standardized test cases. Ultimately, these reliability and resilience concerns must be given even greater attention when studying the transportation-electricity nexus as a combination of two critical infrastructures. For example, Hurricane Sandy demonstrated that emergency preparedness and evacuation capability in the greater New York City area depended on both an operational power grid and a fully functional (electrified) public transportation system (AnonymousDOE 2013; Committee on Increasing National Resilience to Hazards and Disasters and Committee on Science Engineering and Public Policy 2012; Department of Homeland Security 2013; Marcacci 2013; TheWhite House: Office of the Press Secretary 2013).

\section{Supporting a fundamental understanding}

Test cases also serve to support a fundamental understanding of systems beyond their specific instances. On the power system side, the IEEE RTS was specifically designed to have a degree of functional heterogeneity not often found in a typical power system (Grigg et al. 1999). Thus, its study can broaden intuition development. Similarly, it is is well known that the radial structure of power distribution systems leads to fundamentally different behaviors (e.g. low terminal voltages) than the mesh structure in transmission systems (Gomez Exposito et al. 2008; Wood and Wollenberg 2014). Test cases have also played an important role in our fundamental understanding of power grid resilience (Albert et al. 2000; Holme et al. 2002) and synchronization (Arenas et al. 2008; Barrat et al. 2008; Lewis 2011; Newman 2009). Both of which depend heavily on abstracted measures of centrality and degree distribution (Barrat et al. 2008; Lewis 2011; Newman 2009). On the transportation system side, again, usage of specific topologies has been the traditional practice. Some prominent researchers, however, have advocated the need for "investigating fundamental issues of traffic dynamics rather than simulating specific road networks" (Treiber and Kesting 2010). These individual positions on the transportation and power systems suggests that as they become increasingly intertwined infrastructures, it will also become increasingly important to understand how to best plan \& connect them into a single structure (Farid 2015a; Viswanath and Farid 2014). Furthermore, the dynamic of the combined system (i.e. the TEN) will become increasingly interdependent thus requiring new optimization and control techniques for its operation (Farid 2015a; Viswanath and Farid 2014).

\section{Supporting methodological development}

Test cases also serve methodological development of the design, planning and operation of systems well before they are operational. The challenge with large scale systems such as the transportation-electricity nexus is that their behavior emerges often in unexpected ways as they develop (Buede 2009). Consider the case of renewable energy integration. At the level of pilot plant integration, their variability and intermittency has a negligible effect. However, as the penetration rate increases into double digit figures, they have significant technical and economic impacts on the power system (Brouwer et al. 2014; Ela et al. 2009; Holttinen et al. 2012, 2013). These include the need for greater operating reserves, improved operations \& control, and increased marginal costs (Muzhikyan et al. 2015a,b). Thus, test cases can serve to identify characteristic system behavior and provide ample foresight to avoid and mitigate undesirable effects. The recent Abu Dhabi Transportation-Electrification Study used four hypothetical charging topologies and showed the potential for undesirable charging queues and highly variable charging loads (Al Junaibi et al. 2013; Al Junaibi 2013). Consequently, it recommended planning methods such as optimal placement of charging facilities as well as optimization \& control methods within an "Intelligent-Transportation Energy System" (ITES) (Al Junaibi et al. 2013; Al Junaibi 2013). These are further discussed later in Section 'Potential applications of the transportation electrification test case.' Ultimately, the parameterization of systems into test cases supports not just their fundamental understanding but also the development of methods for their enhancement.

\section{Protection of personal data privacy}

Transportation electrification research specifically requires test cases to address personal data privacy concerns. As has been previously reported (Al Junaibi et al. 2013; Junaibi 2013; Junaibi and Farid 2013), electric vehicle integration studies must differentiate between electric vehicles and conventional internal combustion vehicles. Furthermore, each electric vehicle's state of charge must be resolved so as to determine where, when and how much charging is required. These two requirements suggest microscopic rather than macroscopic traffic simulation studies. In addition to these demanding simulation requirements, electric vehicle integration 
studies must track not just the number of vehicles moving from an origin to a destination but also each as it undergoes a sequence of moving and stationary events in a vehicle use case. This is in agreement with trends towards "next generation" traffic simulation concepts that feature multi-modality and multi-agency (Passos et al. 2011).

Consider Fig. 2 where a private EV and an EV Taxi follow a home-commute-work-commute-home use case pattern. While the underlying traffic demand is the same in both cases, several implementations of the EV taxi are possible. During the columns marked in orange, the private EV is likely to choose between parking or charging. Meanwhile, the EV taxi has both of those options but may also roam in between fares, or simply wait in place for further instruction. Thus, the impacts on traffic patterns, charging infrastructure and the subsequent charging loads are likely to differ substantially. Furthermore, an individual's driving behavior in different traffic conditions directly affects the consumption of battery charge (Karabasoglu and Michalek 2013; Raykin et al. 2012).

Gathering such data is tantamount to tracking individual vehicles at every point over the course of the day. While the deployment of intelligent transportation systems and connected vehicle technology is increasingly making such an endeavor possible, it nevertheless raises grave privacy and ethical concerns (Hubaux et al. 2004; Kleberger et al. 2011). Test cases that have a set of "virtual" vehicle itineraries over the course of the day such that they mimic traffic patterns spatially and temporally offer a much more promising research methodology. The potential applications identified in Section 'Potential applications of the transportation electrification test case' can thus continue to develop in ways that ensure a solid understanding of aggregate system behavior while respecting individual data privacy.

\section{Transportation-electrification test case}

Given the rationale above, this section describes a Transportation-Electrification Test Case summarized by

Fig. 3. This includes three structural descriptions: a topology, electric power topology and charging system topology. It also includes a transportation demand and charging demand as system inputs. In developing the test case, a number of desirable characteristics were sought which drive the discussion. These include:

- Completeness - a system consisting of the full scope described in Definition 1.

- Functional Heterogeneity - a system with several complementary modes of electrification

- Moderate Size - a system whose characteristics are large enough to exhibit emergent behavior but small enough to not require excessive computation time

- Regular Topology - a system whose structure leads to regular easy-to-predict aggregate behaviors

- Regular Demand Data - a system whose inputs leads to regular easy-to-predict aggregate behaviors

- Realism - a system which has a strong resemblance to real-life characteristic problems.

- Objectivity - a system which discourages undue bias between scenarios.

That said, the test case was not designed to be "optimal" to achieve any particular performance system objective. Rather, it is meant to elucidate emergent behaviors when simulated. As is discussed further in Section 'Potential applications of the transportation electrification test case', such approaches are left to future applications of the test case. With these considerations in mind, and in the absence of a real-life test case with the same attributes, the hypothetical test case aptly named "Symmetrica" is developed. While its specific characteristics may differ from the reality of specific regions, its characteristics do offer much in developing insight and intuition into the dynamics of a TEN. The test case's numerical figures are presented as comma separated value files which may be accessed as part of this paper's supplementary material or open-sources online (Farid 2015c). The transportation system half of the Symmetrica test case, with slight modification of its values, and omission of the power grid, has been simulated using a previously developed dynamic system model (Farid 2015a; Viswanath and Farid 2014).

\begin{tabular}{|c|c|c|c|c|c|c|c|c|c|}
\hline \multirow[b]{2}{*}{ Person } & \multicolumn{6}{|c|}{ 12:00-7:30am 7:30-8:00am 8:00am-12:00pm12:00-12:15pm 12:15-12:45pm 12:45-1:00pm } & \multirow{2}{*}{$\begin{array}{c}\text { 1:00-5:00pm } \\
\text { Work }\end{array}$} & \multirow{2}{*}{$\begin{array}{c}\text { 5:00-5:30pm } \\
\text { Commute Home }\end{array}$} & \multirow{2}{*}{$\begin{array}{l}5: 30-12 \mathrm{pm} \\
\text { At Home }\end{array}$} \\
\hline & Sleep & Work Commute & Work & Drive to Lunch & Eat Lunch & Drive to Work & & & \\
\hline $\begin{array}{l}\text { Private } \\
\text { Car: } \\
\text { Home } \\
\text { Charging }\end{array}$ & $\begin{array}{c}\text { Charging at } \\
\text { Home? } \\
\text { (Alone?) }\end{array}$ & Drive EV Car & $\begin{array}{c}\text { Charging at } \\
\text { Work? (w/ } \\
\text { Others?) }\end{array}$ & Drive EV Car & $\begin{array}{c}\text { Charging at } \\
\text { Lunch? (w/ } \\
\text { Others?) }\end{array}$ & Drive EV Car & $\begin{array}{c}\text { Charging at } \\
\text { Work? (w/ } \\
\text { Others?) }\end{array}$ & Drive EV Car & $\begin{array}{c}\text { Charging at } \\
\text { Home? } \\
\text { (Alone?) }\end{array}$ \\
\hline $\begin{array}{l}\text { Hired } \\
\text { Taxi: } \\
\text { Public } \\
\text { Charging }\end{array}$ & $\begin{array}{l}\text { Charging at } \\
\text { Taxi Stand } \\
\text { w/ Others }\end{array}$ & Drive Taxi A & $\begin{array}{l}\text { Waiting? } \\
\text { Roaming? } \\
\text { Other Jobs? }\end{array}$ & Drive Taxi A & Waiting? & Drive Taxi A & $\begin{array}{l}\text { Waiting? } \\
\text { Roaming? } \\
\text { Other Jobs? }\end{array}$ & Drive Taxi A & $\begin{array}{l}\text { Charging at } \\
\text { Taxi Stand w/ } \\
\text { Others }\end{array}$ \\
\hline
\end{tabular}

Fig. 2 Contrasting EV Use Cases: Private Car \& Taxi 


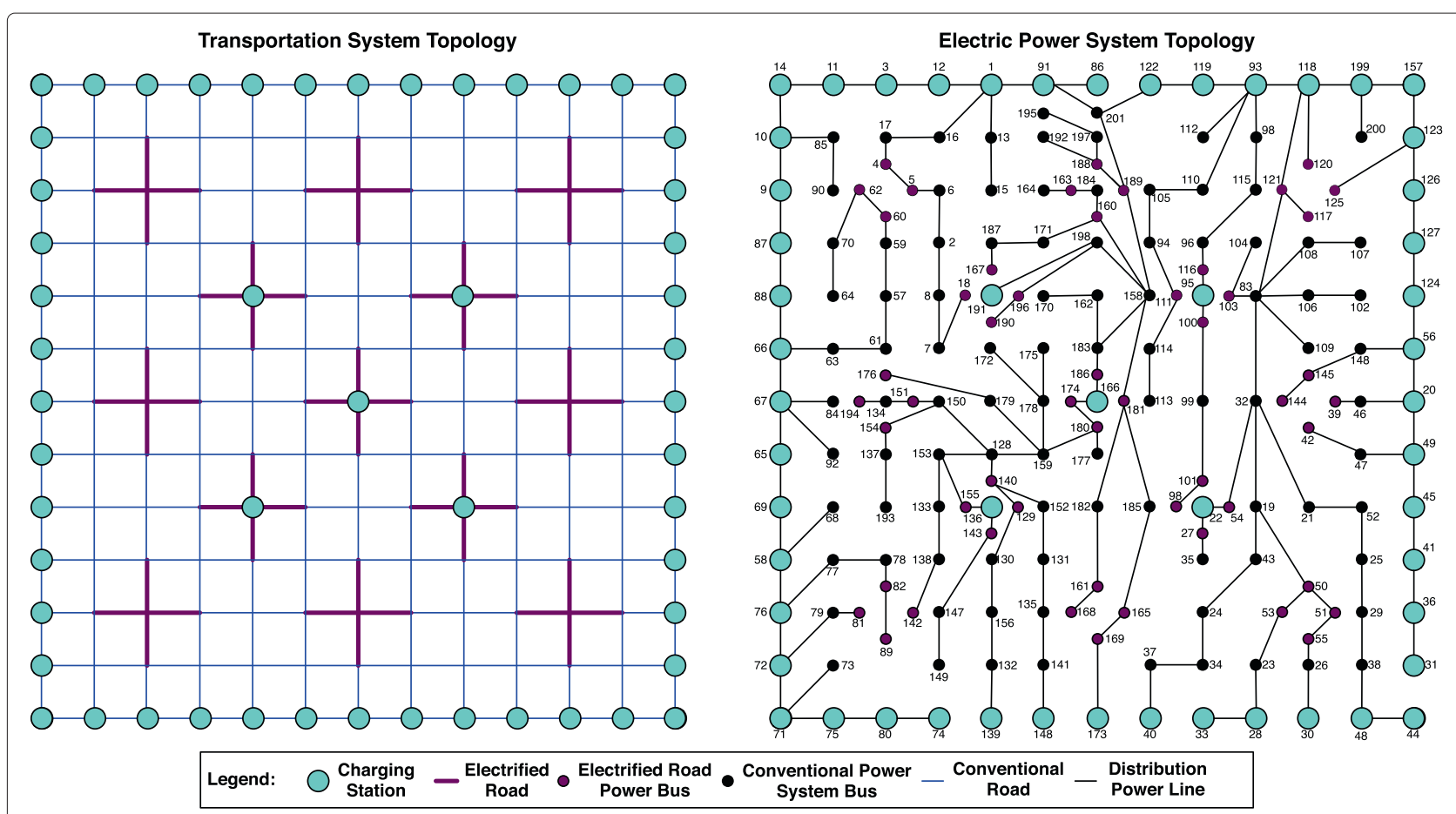

Fig. 3 Topology of the Symmetrica Transportation Electrification Nexus

\section{Transportation system topology}

As shown in Fig. 3, the Symmetrica transportation system topology consists of a suburban $12 \times 12 \mathrm{~km}$ grid with intersections at every kilometer (for a total of 169). Each road segment has a free speed of $60 \mathrm{~km} / \mathrm{hr}$. The corresponding data is provided in a format compatible with several microscopic traffic simulators (Alecsandru 2006; Barcelo 2010; Passos et al. 2011). The choice of a regular suburban grid was made with the understanding that many transportation electrification scenarios occur in this urban or suburban contexts.

\section{Electric power system topology}

As shown in Fig. 3, the Symmetrica electric power system topology consists of a 201-Bus $10 \mathrm{kV}$ distribution system consisting of three feeders. Note that the topology has a Y-bus matrix (i.e. adjacency matrix and impedances) that is a constant multiple of the Y-bus matrix in another power system test case reported earlier in the literature (Manuel de Oliveira de Jesus 2007; Ramirez-Rosado and Bernal-Agustin 1998). Rather than impose any specific line or voltage limits, a power flow analysis can be conducted later to examine the feasibility of the voltage levels and line flows as a consequence of simultaneous electric vehicle charging (Al Junaibi et al. 2013; Al Junaibi 2013; Al Junaibi and Farid 2013; Kassakian et al. 2011). As a significant contribution, these buses were assigned GPS coordinates so as to be co-located with the intersections in the transportation system topology. While it is not necessary to provide GPS coordinates for most power system reliability studies, they are absolutely required for holistic studies of a transportation electricity nexus. The choice of a power distribution system was made with the understanding that most electrified transportation systems connect to distribution nodes and exhibit similar characteristic length scales.

\section{Charging system topology}

The Symmetrica charging system topology was developed to support both plug-in electric vehicles and wireless online electric vehicles (Ahn et al. 2013; Kim et al. 2013). Both modes of charging deliver a maximum of approximately 62.5 MW charging load - the size of a medium capacity generator. The equivalence in the peak charging rate between the two scenarios was introduced to avoid biasing effects on vehicle travel patterns, and power system balance. The details of each scenario are as follows.

\section{Plugin charging topology}

The conventional electrification topology consists of two groups of charging stations. There are 5 charging stations in the city center at coordinates $(4,4),(4,8),(8,4)$, $(8,8)$ and $(6,6)$. These are marked as cyan circles in Fig. 3. Each of these are able to deliver $24 \mathrm{~kW}$ to each of 25 vehicles at a time. In order to include the potential for home charging, a charging station was placed at every intersection along the periphery; each delivering $24 \mathrm{~kW}$ to each of 50 vehicles at a time. It is important to note 
that a given intersection here does not represent an individual home where there may only be 1 or 2 spaces to charge in a garage. Instead, the intersections along the periphery represent all of the homes associated with the vehicles that exited Symmetrica through that intersection. Thus, it is a centralized representation of a distributed charging capacity outside of the city. In theory, full electric vehicle deployment suggests ubiquitous home charging and thus this capacity is effectively infinite. (Every vehicle owner should be able to return home to charge). However, a fair comparison with the online electric vehicle case requires that the installed charging capacity of scenarios be equal. Here, the total installed charging capacity is $(5)(0.24)(25)+(48)(0.024)(30)=64.56 \mathrm{MW}$.

\section{Wireless charging topology}

The online electric vehicle topology consists of 13 groups of electrified road segments which appear in Fig. 3 as magenta-colored $2 \mathrm{~km} \times 2 \mathrm{~km}$ road crosses. Meanwhile, each of these electrified road segments connects to a magenta-colored bus on the right of Fig. 3. Each road segment is able to deliver $48 \mathrm{~kW}$ to each of 25 vehicles at a time. In order to clearly distinguish the differences in system performance between the two modes of electrified transportation, this test case assumes that plugin electric and online electric vehicles are mutually exclusive sets. The wireless charging topology is also capable of delivering up to $(4)(13)(0.048)(25)=62.4 \mathrm{MW}$ of power.

\section{Traffic demand}

The traffic demand is presented as three complementary data sets each representing a different integration scenario.

- Plugin Version: 50 \% conventional vehicles, $50 \%$ plugin electric vehicles

- Online Version: 50 \% conventional vehicles, $50 \%$ online electric vehicles

- Multi-Mode Version: 50 \% conventional vehicles, $25 \%$ plugin electric vehicles, $25 \%$ online electric vehicles

The classification of "conventional", "plugin" and "online" electric vehicle is made on the basis of the nature of the coupling between the vehicle and the charging infrastructure. Conventional vehicles require no such coupling. Plugin electric vehicles couple to charging stations. These represent nodes in both the transportation and electric power system graphs. Online electric vehicles couple to electrified roads. These represent nodes in the electric power system but represent edges in the transportation system. Other vehicle classification systems may be mapped onto these three types. Hybrid electric vehicles (w/o plug-in capability), for example, would appear as "conventional" electric vehicles in this test case.
In all cases, the traffic demand represents a simplification of an average work day. Symmetrica starts the day empty of any vehicles. Vehicles enter from any of the intersections along the symmetric periphery and go to the five work locations which coincide with the five conventional charging stations depicted as cyan circles. The data is presented post-vehicle routing; in other words as a sequence of steps from the periphery to the work location and then back. In such a regular topology, there are many "shortest route" choices between a given origin and destination. For example, there are 6 such routes just from $(0,0)$ to $(2,2)$. The traffic demand consists of all of these shortest routes with the added constraint that such routes must pass through the centers of the electrified road segment crosses depicted in magenta. This ensures that the same traffic demand can be applied in all three data sets without bias. It also serves to more evenly distribute the traffic and not place undue congestion on the electrified roads. Note that the number of routes thus follows an exponential distribution with the required distance between periphery and work location.

The traffic demand makes use of this exponential distribution to generate the timing and congestion in the morning and evening rush hour commutes. For a given origin-destination pair, there are many possible routes. Each of these is initiated every minute, one vehicle at a time, in such a way that they are centered around 8:00 am. A total of 6,086 vehicles are included in the test case. In all, the first vehicles enter Symmetrica at 5:00 am and the end of the morning commute is marked with the last vehicle at $10 \mathrm{am}$. Upon arriving to the five work locations, the vehicles remain there for $8 \mathrm{~h}$ and then return to the Symmetrica periphery intersection from which they entered along the route that they took in the morning. No further assumption is made on the transportation use case (e.g. private usage, taxi, car sharing etc).

\section{Charging demand}

Both plugin and online electric vehicles are treated equally except for their method and duration of charging. They begin their day at a full charge at the maximum battery capacity of $10 \mathrm{kWhr}$. They are assumed to discharge power at a rate of $24 \mathrm{~kW}$ when moving at the road free speed of $60 \mathrm{~km} / \mathrm{hr}$. These values are within the physical limits of current technology. The online electric vehicles charge only while driving over electrified road segments. The plugin electric vehicles charge immediately upon arrival to work and upon return to home for a duration sufficient to return to full charge.

\section{Test case summary: adherence to desirable characteristics}

The Symmetrica test case provided here can now be summarized with respect to the qualitatively desirable characteristics mentioned at the beginning of the section. 
- Completeness - The Symmetrica test case consists of structural elements that meet the full scope of Definition 1.

- Functional Heterogeneity - The Symmetrica test case includes both online and plug-in modes of electrified transportation.

- Moderate Size - The Symmetrica test case is characterized by 169 nodes and 6,086 vehicles. This scale of numbers has been shown to exhibit emergent behaviors without excessive computation time (Farid 2015a).

- Regular Topology - The Symmetrica test case topology has a symmetrical structural and leads to easy-to-predict aggregate behaviors.

- Regular Demand Data - The Symmetrica test case demand data has a symmetrical shape in time and leads to regular easy-to-predict aggregate behaviors.

- Realism - The Symmetrica test case has a meshed transportation grid to resemble urban city blocks.

- Objectivity - The Symmetrica test case has the same number of vehicles in all three traffic demand data sets. The plug-in charging capacity is approximately the same capacity as the online-charging capacity.

\section{Potential applications of the transportation electrification test case}

The integrated assessment results from the Abu Dhabi electric vehicle integration study motivated the need for an Intelligent Transportation-Energy System (Al Junaibi et al. 2013; Junaibi 2013) which makes coordinated planning and operations time scale decisions across both domains. Some of these potential applications are identified as a roadmap for many future contributions to transportation electrification systems research.

\section{Planning applications}

In the planning time scale, the Abu Dhabi electric vehicle integration study showed that the planning of the charging system as the connector of the two infrastructure systems is highly influential in applying or mitigating the overall performance of the TEN (Al Junaibi et al. 2013; Al Junaibi 2013). It was clear that any transportation electrification scenario would have to match the spatial layout and capacity of the electrified transportation use cases to the spatial layout and capacity of the charging infrastructure. One interesting topic is the viability of a radial power grid to serve a meshed transportation network. The investment cost associated with building the charging infrastructure depends very heavily on the number of charging stations and electrified roads, their capacity to charge multiple vehicles simultaneously and the rate at which they do so. Furthermore, particularly high charging loads may require upgrades to power lines and transformers. These investment costs must be matched to the expected adoption or demand for electrified transportation recognizing that inadequate charging infrastructure can degrade the traveler's experience and degrade the future revenue potential. This balanced view of transportation and power system requirements lends itself to $\mathrm{ROI}$ and operations research methods.

\section{Operations management applications}

In the operations time scale, it showed that five electric vehicle decisions were fundamentally coupled as shown in Table 1 (Al Junaibi et al. 2013; Farid 2015a; Junaibi 2013).

How these decisions are made affects traffic congestion, electric vehicle utilization, charging loads and of course the three traditional power system operations objectives of frequency control, line limit control, and voltage control. Therefore, highly granular approaches to shifting the timing, routing, or charging of electric vehicle behavior could cause aggregate system performance improvements. These improvements have different monetary values in private, public and commercial use cases. Furthermore, there exist several opportunities to find optimality across multiple stakeholders. For example, fleet operators or electrified parking lots can coordinate their activities with utilities or curtailment service providers (Palensky and Dietrich 2011; Siano 2014; Strbac 2008). In all, Intelligent Transportation-Energy Systems present a rich area for potential applications.

\section{Conclusion}

This work has recognized that transportation electrification represents a rich field in which to conduct systems research. To that end, it has contributed a transportation electricity nexus test case; aptly named "Symmetrica". It consists of transportation, electric power, and charging

Table 1 Intelligent transportation-energy system operations decisions in the transportation electricity nexus (Al Junaibi et al. 2013; Farid 2015a; Junaibi 2013)

- Vehicle Dispatch: When a given EV should undertake a trip (from origin to destination)

- Route Choice: Which set of roads and intersections it should take along the way

- Charging Station Queue Management: When \& where it should charge in light of real-time development of queues

- Coordinated Charging: At a given charging station, when the EVs should charge to meet customer departure times and power grid constraints

- Vehicle-2-Grid Stabilization: Given the dynamics of the power grid, how can the EVs be used as energy storage for stabilization 
system topologies in addition to traffic and charging demand data. The need for a test case was formulated on the basis of a five point argument including 1.) the usage of power systems test cases, 2.) the preservation of critical infrastructure security, 3.) the support of a fundamental understanding of the transportation-electricity nexus, 4.) the support of methodological development and 5.) the protection of personal data privacy. The work concluded with several avenues for future research particularly in planning and operations for an "Intelligent Transportation-Energy System".

\section{Competing interests}

The author declares that he has no competing interests.

\section{Authors' contributions}

This paper's contribution is two fold: 1.) an argument for the need for a transportation electrification test case 2.) a transportation electrification test case named Symmetrica.

\section{Acknowledgements}

The author do not wish to make any acknowledgements.

Received: 26 June 2015 Accepted: 6 October 2015

Published online: 16 October 2015

\section{References}

Ahn S, Suh NP, Cho DH (2013) Charging up the road. Spectrum IEEE 50(4):48-54. doi:10.1109/MSPEC.2013.6481699

Allan RN, Billinton R, Abdel-Gawad NMK (1986) The ieee reliability test system???extensions to and evaluation of the generating system. Power Eng Rev IEEE PER-6(11):24-24. doi:10.1109/MPER.1986.5527462

Albert R, Jeong H, Barabási AL (2000) Error and attack tolerance of complex networks. Nature 406(6794):378-382. doi:10.1038/35019019

Al Junaibi R (2013) Technical Feasibility Assessment of Electric Vehicles in Abu Dhabi. Master's thesis, Masdar Institute of Science and Technology Engineering Systems \& Management Department

Al Junaibi R, Farid AM (2013) A Method for the Technical Feasibility Assessment of Electrical Vehicle Penetration. In: 7th Annual IEEE Systems Conference. IEEE, Orlando, FL, USA. pp 1-6

Al Junaibi R, Viswanath A, Farid AM (2013) Technical Feasibility Assessment of Electric Vehicles: An Abu Dhabi Example. In: 2nd IEEE International Conference on Connected Vehicles and Expo, Las Vegas, NV, USA. pp 410-417

Alecsandru CD (2006) A Stochastic Mesoscopic Cell-Transmission Model for Operational Analysis of Large-Scale Transportation Networks. PhD thesis, Louisiana

Anair D, Mahmassani A (2012) State of Charge: Electric Vehicles' Global Warming Emissions and Fuel-Cost Savings across the United States. Technical Report April, Union of Concerned Scientists: Citizens and Scientists for Environmental Solutions, Cambridge, MA, USA

Anonymous-DOE (2013) Energy department partners with state of new jersey to study ways to improve the reliability of new jersey's transit system in aftermath of superstorm sandy. Technical report, U.S. Department of Energy http://www.energy.gov/articles/energy-department-partnersstate-new-jersey-study-ways-improve-reliability-new-jersey-s

Arenas A, Diaz-Guilera A, Kurths J, Moreno Y, Zhou C (2008) Synchronization in complex networks. Phys Rep 469(3):93-153. doi:10.1016/j.physrep.2008.09.002

Barcelo J, Kuwahara M (2008) Traffic Data Collection and Its Standardization. Springer, New York. p 194

Barrat A, Barthelemy M, Vespignani A (2008) Dynamical processes on complex networks. Cambridge University Press, Cambridge, UK

Barcelo J (2010) Fundamentals of Traffic Simulation. Springer, New York. p 440

Brouwer AS, van den Broek M, Seebregts A, Faaij A (2014) Impacts of large-scale Intermittent Renewable Energy Sources on electricity systems, and how these can be modeled. Renew Sust Energ Rev 33:443-466
Buede DM (2009) The Engineering Design of Systems: Models and Methods. 2nd edn. Wiley, Hoboken, NJ

Clement-Nyns K, Haesen E, Driesen J (2010) The impact of charging plug-in hybrid electric vehicles on a residential distribution grid. Power Syst IEEE Trans 25(1):371-380. doi:10.1109/TPWRS.2009.2036481

Committee on Increasing National Resilience to Hazards and Disasters, Committee on Science Engineering and Public Policy (2012) Disaster Resilience: A National Imperative. The National Academies Press, Washington, DC, USA. pp 1-261

Department of Homeland Security (2013) National Infrastructure Protection Plan: Partnering for Critical Infrastructure Security and Resilience. Technical report, Department of Homeland Security, Washington, DC, USA

Dyke KJ, Schofield N, Barnes M (2010) The impact of transport electrification on electrical networks. Ind Electron IEEE Trans 57(12):3917-3926. doi:10.1109/TIE.2010.2040563

Ela E, Milligan M, Parsons B, Lew D, Corbus D (2009) The evolution of wind power integration studies: Past, present, and future. In: Power Energy Society General Meeting, 2009. PES '09. IEEE. pp 1-8

Erol-Kantarci M, Sarker JH, Mouftah HT (2012) Quality of service in Plug-in Electric Vehicle charging infrastructure. In: Electric Vehicle Conference (IEVC), 2012 IEEE International. IEEE, Greenville, SC, USA. pp 1-5

Farid AM (2014) Static Resilience of Large Flexible Engineering Systems: Part II - Axiomatic Design Measures. In: 4th International Engineering Systems Symposium. Stevens Institute of Technology, Hoboken, NJ. pp 1-8

Farid AM (2015a) Electrified transportation system performance: Conventional vs. online electric vehicles. In: Suh NP, Cho DH (eds). Electrification of Ground Transportation Systems for Environment and Energy Conservation, Chapter 22. MIT Press, Cambridge, MA. pp 1-25

Farid AM (2015b) LIINES Datasets Repository. In: Laboratory for Intelligent Integrated Networks of Engineering Systems. Thayer School of Engineering at Dartmouth, Hanover, NH, USA. http://amfarid.scripts.mit. edu/Datasets/index.html

Farid AM (2015c) LIINES Transportation Electrification System Dataset Repository. In: Laboratory for Intelligent Integrated Networks of Engineering Systems. Thayer School of Engineering at Dartmouth, Hanover, NH, USA. http://amfarid.scripts.mit.edu/Datasets/TES-Data/index.php

Farid AM (2015d) Static Resilience of Large Flexible Engineering Systems: Axiomatic Design Model. IEEE Systems Journal (in press) PP(99):1-12

Galus MD, Waraich RA, Noembrini F, Steurs K, Georges G, Boulouchos K, Axhausen KW, Andersson G (2012) Integrating power systems, transport systems and vehicle technology for electric mobility impact assessment and efficient control. IEEE Trans Smart Grid 3(2):934-949

Gan L, Topcu U, Low S (2013) Optimal decentralized protocol for electric vehicle charging. Power Systems, IEEE Conference on 28(2):940-951

Gomez Exposito A, Conejo AJ, Canizares C (2008) Electric Energy Systems: Analysis and Operation. The electr. CRC, Boca Raton, Fla

Gong Q, Midlam-Mohler S, Serra E, Marano V, Rizzoni G (2013) PEV Charging Control for a Parking Lot Based on Queuing Theory. In: 2013 American Control Conference. IEEE, Washington, DC. pp 1126-1131

Grigg C, Wong P, Albrecht P, Allan R, Bhavaraju M, Billinton R, Chen Q, Fong C, Haddad S, Kuruganty S, Li W, Mukerji R, Patton D, Rau N, Reppen D, Schneider A, Shahidehpour M, Singh C (1999) The IEEE Reliability Test System-1996. A report prepared by the Reliability Test System Task Force of the Application of Probability Methods Subcommittee. Power Syst IEEE Trans 14(3):1010-1020. doi:10.1109/59.780914

Haimes YY, Crowther K, Horowitz BM (2008) Homeland security preparedness: Balancing protection with resilience in emergent systems. Syst Eng 11(4):287-308. doi:10.1002/sys

Harary F, Hayes JP (1993) Edge fault tolerance in graphs. Networks 23(2):135-142

Holme P, Kim B, Yoon C, Han S (2002) Attack vulnerability of complex networks. Phys Rev E 65(5):56101-56109. doi:10.1103/physreve.65.056109

Holttinen H, Malley MO, Dillon J, Flynn D (2012) Recommendations for Wind Integration Studies - IEA Task 25. Technical report, International Energy Agency, Helsinki

Holttinen $\mathrm{H}$, Orths A, Abilgaard H, van Hulle F, Kiviluoma J, Lange B, O'Malley M, Flynn D, Keane A, Dillon J, Carlini EM, Tande JO, Estanquiro A, Lazaro EG, Soder L, Milligan M, Smith C, Clark C (2013) IEA Wind Export Group Report on Recommended Practices Wind Integration Studies. Technical report, International Energy Agency, Paris, France

Hubaux JP, Capkun S, Luo J (2004) The security and privacy of smart vehicles. IEEE Secur Priv Mag 2(LCA-ARTICLE-2004-007):49-55 
IEEE PES Distribution System Analysis Subcommittee's Distribution Test Feeder Working Group (2015) Distribution Test Feeders. In: IEEE Power and Energy Society. http://ewh.ieee.org/soc/pes/dsacom/testfeeders/

Ip WH, Wang D (2011) Resilience and friability of transportation networks: Evaluation, analysis and optimization. IEEE Syst J 5(2):189-198. doi:10.1109/jsyst.2010.2096670

Karabasoglu O, Michalek J (2013) Influence of driving patterns on life cycle cost and emissions of hybrid and plug-in electric vehicle powertrains. Energy Policy 60(0):445-461. doi:10.1016/j.enpol.2013.03.047

Kassakian JG, Schmalensee R, Desgroseilliers G, Heidel TD, Afridi K, Farid AM, Grochow JM, Hogan WW, Jacoby HD, Kirtley JL, Michaels HG, Perez-Arriaga I, Perreault DJ, Rose NL, Wilson GL, Abudaldah N, Chen M, Donohoo PE, Gunter SJ, Kwok PJ, Sakhrani VA, Wang J, Whitaker A, Yap XL, Zhang RY, Technology MI (2011) The Future of the Electric Grid: An Interdisciplinary MIT Study. MIT Press, Cambridge, MA. pp 1-280.

http://web.mit.edu/mitei/research/studies/documents/electric-grid-2011/ Electric_Grid_Full_Report.pdf

Kavasseri R, Ababei C (2015) REDS: REpository of Distribution Systems. In: IEEE Power and Energy Society. Marquette University, Milwaukee, WI

Kempton W, Tomić J (2005) Vehicle-to-grid power implementation: From stabilizing the grid to supporting large-scale renewable energy. J Power Sources 144(1):280-294. doi:10.1016/j.jpowsour.2004.12.022

Kim J, Kim J, Kong S, Kim H, Suh IS, Suh NP, Cho DH, Kim J, Ahn S (2013) Coil design and shielding methods for a magnetic resonant wireless power transfer system. Proc IEEE 101(6):1332-1342. doi:10.1109/JPROC.2013.2247551

Kleberger P, Olovsson T, Jonsson E (2011) Security aspects of the in-vehicle network in the connected car. In: Intelligent Vehicles Symposium (IV), 2011 IEEE. IEEE, Baden-Baden, Germany. pp 528-533

Lewis TG (2011) Network Science: Theory and Applications. Wiley, Hoboken, N

Litman T (2013) Comprehensive Evaluation of Transport Energy Conservation and Emission Reduction Policies. Transp Res art: Policy Pract 47:1-23

Lopes JAP, Soares FJ, Almeida PMR (2011) Integration of Electric Vehicles in the Electric Power System. Proc IEEE 99(1):168-183. doi:10.1109/JPROC.2010.2066250

Ma Z, Callaway D, Hiskens I (2012) Optimal Charging Control for Plug-In Electric Vehicles. In: Control and Optimization Methods for Electric Smart Grids. Springer, Berlin, Germany. pp 259-273

Manuel de Oliveira de Jesus P (2007) Remuneration of distributed generation: A holistic approach. PhD thesis, Faculdade de Engharia Universidade de Porto

Marcacci S (2013) Doe and new jersey developing first us transit system microgrid. Technical report, Clean Technica. http://cleantechnica.com/ 2013/08/28/doe-and-new-jersey-developing-first-us-transit-systemmicrogrid/

Muzhikyan A, Farid AM, Youcef-Toumi K (2015a) An Enterprise Control Assessment Method for Variable Energy Resource Induced Power System Imbalances Part 1: Methodology. IEEE Trans Ind Electron 62(4):2448-2458

Muzhikyan A, Farid AM, Youcef-Toumi K (2015b) An Enterprise Control Assessment Method for Variable Energy Resource Induced Power System Imbalances Part 2: Results. IEEE Trans Ind Electron 62(4):2459-2467

Najjar W, Gaudiot JL (1990) Network resilience: a measure of network fault tolerance. IEEE Trans Comput 39(2):174-81. doi:10.1109/12.45203

Newman M (2009) Networks: An Introduction. Oxford University Press, Oxford, UK

Palensky P, Dietrich D (2011) Demand side management: demand response, intelligent energy systems, and smart loads. Ind Inf IEEE Trans 7(3):381-388

Pasaoglu G, Honselaar M, Thiel C (2012) Potential vehicle fleet CO2 reductions and cost implications for various vehicle technology deployment scenarios in Europe. Energy Policy 40:404-421. doi:10.1016/j.enpol.2011.10.025

Passos LS, Rossetti RJF, Kokkinogenis Z (2011) Towards the next-generation traffic simulation tools: a first appraisal. In: Information Systems and Technologies (CISTI), 2011 6th Iberian Conference On. IEEE, Chaves, Portugal. pp 1-6

Pieltain Fernandez L, Roman TGS, Cossent R, Domingo CM, Frias P (2011) Assessment of the impact of plug-in electric vehicles on distribution networks. Power Syst IEEE Trans 26(1):206-213 doi:10.1109/TPWRS.2010.2049133

Pointon J (2012) The Multi-Unit Dwelling Vehicle Charging Challenge. In: Electric Vehicles Virtual Summit 2012. The Smart Grid Observer Vol. 69

Qian K, Zhou C, Allan M, Yuan Y (2011) Modeling of load demand due to EV battery charging in distribution systems. Power Syst IEEE Trans 26(2):802-810. doi:10.1109/TPWRS.2010.2057456
Ramirez-Rosado IJ, Bernal-Agustin JL (1998) Genetic algorithms applied to the design of large power distribution systems. Power Syst IEEE Trans 13(2):696-703

Raykin L, Roorda MJ, MacLean HL (2012) Impacts of driving patterns on tank-to-wheel energy use of plug-in hybrid electric vehicles. Transp Res Part D: Transp Environ 17(3):243-250. doi:10.1016/j.trd.2011.12.002

Rosenkrantz DJ, Goel S, Ravi SS, Gangolly J (2009) Resilience metrics for service-oriented networks: a service allocation approach. IEEE Trans Serv Comput 2(3):183-196. doi:10.1109/tsc.2009.18

Saber AY, Venayagamoorthy GK (2011) Plug-in Vehicles and Renewable Energy Sources for Cost and Emission Reductions. Ind Electron IEEE Trans 58(4):1229-1238. doi:10.1109/TIE.2010.2047828

Salles RM, Marino DA (2011) Strategies and metric for resilience in computer networks. Comput J 55(6):728-739. doi:10.1093/comjnl/bxr110

Siano P (2014) Demand response and smart grids-a survey. Renew Sust Energ Rev 30:461-478. doi:10.1016/j.rser.2013.10.022

Skippon S, Garwood M (2011) Responses to battery electric vehicles: UK consumer attitudes and attributions of symbolic meaning following direct experience to reduce psychological distance. Transp Res Part D: Transp Environ 16(7):525-531. doi:10.1016/j.trd.2011.05.005

Sonoda T, Kawaguchi K, Kamino Y, Koyanagi Y, Ogawa H, Ono H (2012) Environment-conscious urban design simulator "clean mobility simulator" - traffic simulator that includes electric vehicles. Mitsubishi Heavy Ind Tech Rev 49(1):78-83

Sortomme E, Hindi MM, MacPherson SDJ, Venkata SS (2011) Coordinated charging of plug-in hybrid electric vehicles to minimize distribution system losses. Smart Grid IEEE Trans 2(1):198-205. doi:10.1109/TSG.2010.2090913

Sovacool BK, Hirsh RF (2009) Beyond batteries: An examination of the benefits and barriers to plug-in hybrid electric vehicles (PHEVs) and a vehicle-to-grid (V2G) transition. Energy Policy 37(3):1095-1103

Soylu S (2011) Electric Vehicles - The Benefits and Barriers. Intech Open Access Publisher, Rijeka, Croatia

Strbac G (2008) Demand side management: Benefits and challenges. Energy Policy 36(12):4419-4426. doi:10.1016/j.enpol.2008.09.030

Subcommittee PM (1979) leee reliability test system. Power Apparatus Syst IEEE Trans PAS-98(6):2047-2054. doi:10.1109/TPAS.1979.319398

Su W, Rahimi-eichi H, Zeng W, Chow M-Y (2012) A Survey on the Electrification of Transportation in a Smart Grid Environment. IEEE Trans Ind Inf 8(1):1-10

Treiber M, Kesting A (2010) An open-source microscopic traffic simulator. Intell Transp Syst Mag IEEE 2(3):6-13. doi:10.1109/MITS.2010.939208

Treiber M, Kesting A (2013) Traffic Flow Dynamics: Data, Models and Simulation. Springer, Heidelberg, New York. p 503

The White House: Office of the Press Secretary (2013) Presidential Policy Directive: Critical Infrastructure Security and Resilience (PPD-21). Technical report, The White House, Washington, D.C. United states http://www. whitehouse.gov/the-press-office/2013/02/12/presidential-policydirective-critical-infrastructure-security-and-resil

University of Washington Electrical Engineering (2015) Power Systems Test Case Archive. http://www.ee.washington.edu/research/pstca/. Accessed 1 Aug 2015

Viswanath A, Farid AM (2014) A Hybrid Dynamic System Model for the Assessment of Transportation Electrification. In: American Control Conference, 2014. IEEE, Portland, Oregon. pp 1-7

Whitson JC, Ramirez-Marquez JE (2009) Resiliency as a component importance measure in network reliability. Reliab Eng Syst Safety 94(10):1685-1693. doi:10.1016/j.ress.2009.05.001

Wood AJ, Wollenberg BF (2014) Power Generation, Operation, and Control. 3rd edn. Wiley, Hoboken, NJ, USA

Yang Z, Wu Y (2012) Projection of automobile energy consumption and CO 2 emissions with different propulsion/fuel system scenarios in Beijing. In: Remote Sensing, Environment and Transportation Engineering (RSETE), 2012 2nd International Conference On. IEEE, Nanjing, Jiangsu, China. pp 2012-2015

Zimmerman RD, Murillo-Sanchez CE, Thomas RJ (2011) MATPOWER: Steady-State Operations, Planning, and Analysis Tools for Power Systems Research and Education. IEEE Trans Power Syst 26(1):12-19 